\title{
Measures of Community Well-Being: a Template
}

\author{
Tyler J. VanderWeele ${ }^{1,2}$
}

Received: 30 May 2019 / Accepted: 8 August 2019/Published online: 26 August 2019

(C) The Author(s) 2019

\begin{abstract}
A proposal is put forward for a measure of community well-being that can be adapted to numerous specific contexts. The community well-being measure extends beyond simple measures of community satisfaction which are often currently employed. The proposed measure includes items in six domains relevant to community well-being: flourishing individuals, good relationships, proficient leadership, healthy practices, satisfying community, and strong mission. Adaptation of the measure for a variety of contexts is provided so that the proposed approach can be used in nations, cities, neighborhoods, families, workplaces, schools, and religious communities. Discussion is given to the complex relationships between individual and community well-being, and how measures of community well-being may be useful for tracking and assessment or reflection purposes, and how it might ultimately be used for the improvement of community well-being.
\end{abstract}

Keywords Community well-being · Flourishing $\cdot$ Neighborhoods · Social relationships · Subjective well-being $\cdot$ Workplace

\section{Introduction}

Interest in well-being research and promotion has expanded dramatically in past decades. Much of the progress with respect to the measurement of well-being concerns individual level measures. Numerous instruments and scales have been developed, have been validated for use in various settings, and are being employed in research and in government and non-governmental tracking (cf. National Research Council 2013; OECD 2013; Allin and Hand 2017; VanderWeele 2017). There has also been considerable interest in community well-being (Phillips and Wong 2017). Although this has not expanded as quickly or dramatically as individual level research and measures,

Tyler J. VanderWeele

tvanderw@hsph.harvard.edu

1 Harvard T.H. Chan School of Public Health, 677 Huntington Avenue, Boston, MA 02115, USA

2 Human Flourishing Program, Harvard University, Cambridge, MA 02138, USA 
there has been a rich set of conceptualizations and discussions concerning community well-being also (cf. Hay 1996; Chanan 2002; McHardy and O'Sullivan 2004; Prilleltensky and Prilleltensky 2006; Cox et al. 2010; Lee and Kim 2016; Phillips and Wong 2017). National government and international organizations also track various individual-level objective measures including education, access to health care, political participation, crime and safety, life expectancy, literacy, etc., which, when aggregated, are arguably also constitutive components of communal well-being. Environmental assessments, cultural offerings, infrastructure, and national debt which can only be defined at the aggregate level are also often tracked. While there is still tremendous scope for improvement in assessing both individual and community objective measures and as well as individual subjective well-being measures, the tracking of community-related subjective well-being is arguably yet further behind in its development.

The present paper will propose a general framework to assess subjective community well-being. The proposed conceptualization will be relevant at the national level, but relevant also at the level of more local communities including, for example, neighborhoods, cities, families, workplaces, schools, and religious communities. These distinct community contexts, in spite of their differences, also have much in common including the centrality of relationships, the need for good leadership, the importance of practices and structures that allow the community to function well, and a strong sense of mission, all hopefully leading to a satisfying experience of the community itself. A template for community well-being will be proposed, and then adapted to fit these various national, city, neighborhood, workplace, family, school, and religious community contexts, and the template could be extended also to yet further settings. There is of course likely some loss in attempting a general template for community well-being. The concerns of a family are different from those of a workplace or of a nation. However, as will be discussed further below, much of what is distinct across these settings in terms of community wellbeing arguably concerns the objective measures that are relevant in each context. Much of what is subjective - for example, the community seeming to function well and providing a sense of belonging - is arguably similar. In all of these settings, a thriving community will require flourishing individuals, good relationships, proficient leadership, healthy practices, a strong mission, and satisfying community. The material that is developed below is exploratory in nature and is intended to help clarify the domains, and possible items, that might be used to more holistically assess community subjective well-being. Future work will connect the proposed conceptualization to other theoretical constructs, and will examine the psychometric properties of the proposed measure.

\section{Conceptual Background}

A community's flourishing might be understood as a state in which all aspects of the community's life are good. This includes both objective and subjective aspects, both at the individual and at the aggregate or communal levels (see Fig. 1) (cf. Lee and Kim 2016). As noted above, numerous individual and communal objective measures have been developed and are routinely being tracked; and considerable progress has been made at the measurement of individual subjective well-being (National Research Council 2013; OECD 2013; Allin and Hand 2017). What is underdeveloped are community subjective well-being measures. A review by Kim and Lee (2014) of 53 


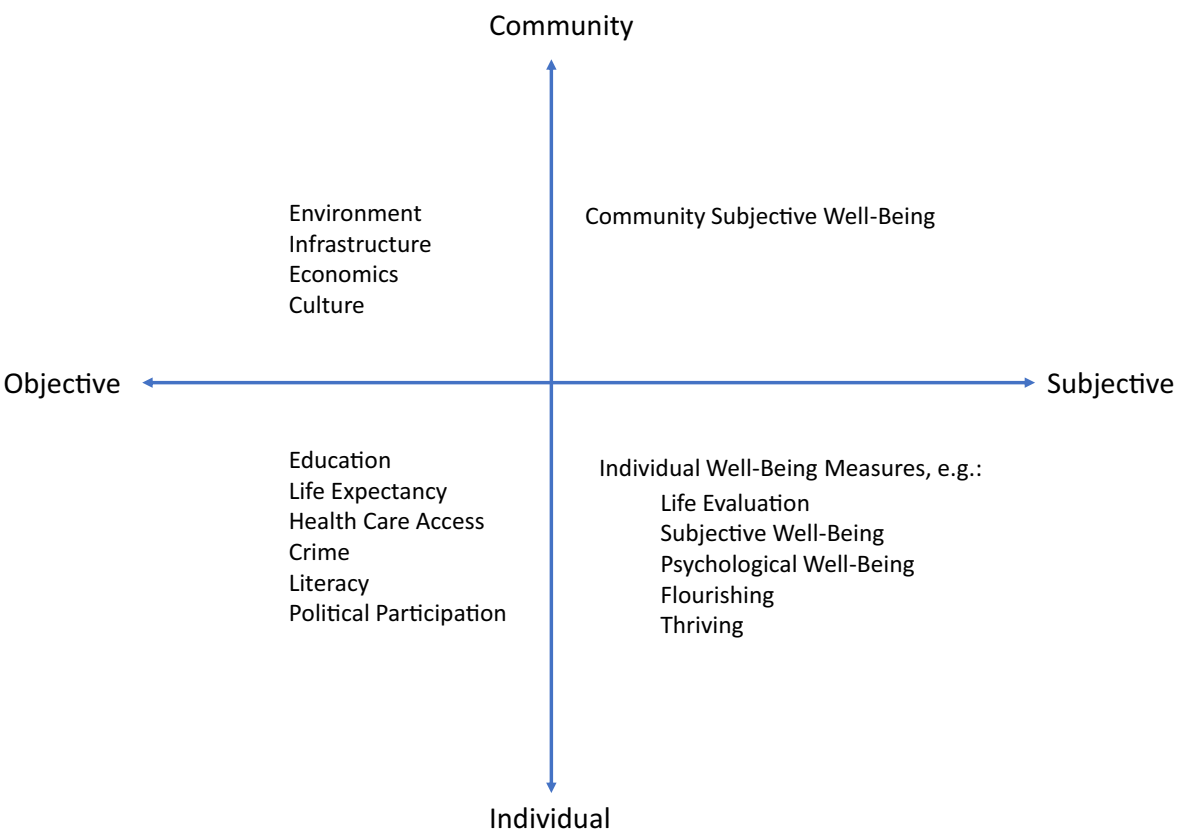

Fig. 1 Joint dimensions of communal vs. individual, and objective vs. subjective assessments of well-being

community measures concluded that despite efforts to include objective and subjective elements, there are still far more objective indicators than subjective. It is the communal subjective measures that will be the focus here. We will refer to this as "community subjective well-being" (or occasionally "community well-being" for short ${ }^{1}$ ) and distinguish it from the broader concept of communal flourishing encompassing both objective and subjective dimensions (i.e. "all aspects").

Much of what is available with regard to measures of subjective community wellbeing concerns satisfaction with the community (Sirgy et al. 2010; Lee and Kim 2016). Sample items include, for example (if the area around the city of Flint were under consideration as the community) (cf. Sirgy et al. 2010): "Overall how satisfied are you with the quality of life in the Flint area?" or "To what extent do you enjoy living in the Flint area?" or "How would you rate the Flint area as a desirable place to live?" Alternatively, other items might assess satisfaction with aspects of a community's culture, community life, administration, or infrastructure (Lee and Kim 2016). But we may ask whether this is this sufficient? Satisfaction is no doubt an important part of community well-being, but relying on satisfaction alone to assess community wellbeing seems problematic for several reasons. First, satisfaction may be high if someone is simply able to get what they want, rather than because the community is good or

\footnotetext{
${ }^{1}$ The shorthand "community well-being" for "community subjective well-being" is perhaps somewhat an abuse of language. The terms "well-being" and "flourishing" are themselves often used almost interchangeably and "community well-being" might thus itself be understood as "a state in which all aspects of the community's life are good." However, because of the rise of the positive psychology movement and its use of the term "well-being", expressions employing "well-being" now carry a strong subjective connotation and thus the slight abuse of language inherent in the shorthand "community well-being" is perhaps somewhat justified.
} 
well-functioning. An employee may be satisfied with their workplace not because of a well-functioning company with good working relationships contributing to the wellbeing of the world, but simply because they are well paid and get to do what they like to do each day. The concept of community well-being would include, but seems to extend beyond, satisfaction. Second, satisfaction with the community may, in many contexts, be a "lagging indicator", with declines in community well-being causing declines in satisfaction in the long-run but potentially taking time to set in. The community's wellbeing may decline for some time without substantially affecting satisfaction, due to past memories, loyalties, a slowness to change perceptions, or again because it takes time for declines in community well-being to substantially adversely affect the experience of the individual. Third, at a conceptual level, satisfaction alone does not tell us what constitutes a good community, only whether individuals are satisfied with it. Satisfaction with a community is undoubtedly important but the notion of community wellbeing seems to extend beyond simply being satisfied with the community.

The measure of community subjective well-being that will be proposed below is based around six distinct domains that include, but extend beyond, satisfaction with the community. These domains are: flourishing individuals, good relationships, proficient leadership, healthy practices, satisfying community, and strong mission. The first domain, flourishing individuals, of course concerns the individual members of the community themselves; the second domain concerns relations between these individuals; the third domain concerns relations specifically with those in authority; the fourth domain concerns the structures and practices governing these various relations; the fifth domain concerns the extent to which these relations and structures give rise to a satisfying community; and the sixth domain concerns the extent to which these relations and structures relate to some further mission or end. Before we introduce the measures and items that are proposed we will briefly consider the motivation for each domain and the various items in turn.

At the heart of every community are the individuals of which it is composed. Communal well-being requires, to some extent at least, the well-being of its members. Communal well-being extends beyond just the aggregate of individual well-being, but it is arguably not independent of this. It would be odd to say that a community is thriving if its individual members are not. We will return, in the discussion below, to the conceptual and causal relations between individual and communal well-being, but at the very least, the well-being of a community is made up in part by the well-being of its members. Good community is constituted in part by flourishing individuals.

Perhaps even more central to the notion of communal well-being is the importance of good relationships. There should be close relationships in the community; each person in the community should be respected as a person and trusted. A thriving community will be one in which each person contributes to the well-being of others in the community. Good community is constituted in part by good relationships.

For a community to thrive and to do so long-term it will also be important to have good leadership. Those in positions of power and authority should care about the wellbeing of everyone in the community and of the community itself. The leaders should have the skill and understanding that is needed to lead the community well and should be of sufficient character and consistency that they can be relied upon to do what is right. They should be able to inspire others with their vision for the community's wellbeing. Good community is thus constituted in part by proficient leadership. 


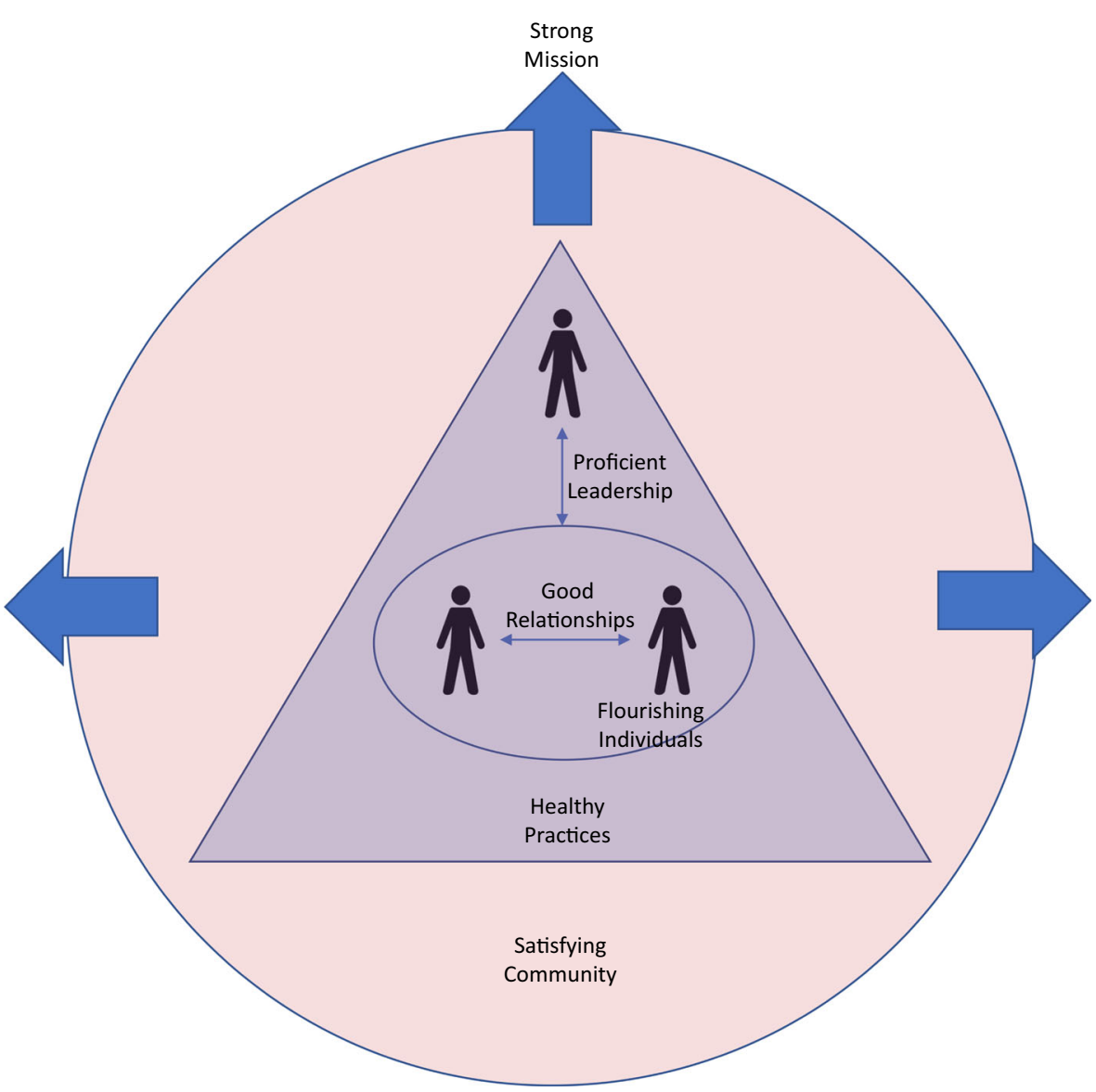

Fig. 2 Conceptualization of community well-being involving the six domains of: flourishing individuals, good relationships, proficient leadership, healthy practices, satisfying community, and strong mission

A well-functioning community will also have healthy practices. There should be structures and practices in place that allow relationships to develop and strengthen, that allow the community to sustain itself, that allow for the appropriate handling of conflicts and disputes, and that allow the community to attain its primary goals. Good community is thus constituted in part by healthy practices.

The community itself should ideally be satisfying to be a part of. In most cases, the absence of this will indicate that something is wrong. Each person should have a sense of welcome and belonging in the community and it should be possible for each person to become more integrated over time. The community should be such that each person thinks that it is a good community to be a part of. Good community is thus constituted in part by satisfying community.

Finally, a good community should be fulfilling its purpose or function, whatever that may be. A good community will be one that somehow contributes to the world to make it a better place. The community's purpose or mission would ideally be clear to everyone. Moreover, the community is thriving, as a community, if the community is able to do more together than the sum of what each could accomplish individually and 
if everyone is needed for the community to fulfill its goals and purposes. Good community is thus constituted in part by a strong mission. ${ }^{2}$

The six domains that the measure below will attempt to assess are thus: flourishing individuals, good relationships, proficient leadership, healthy practices, satisfying community, and strong mission. See Fig. 2 for a diagrammatic representation. In each of these domains participants will be asked to evaluate the community itself, not simply their own satisfaction with it. Even in the "satisfying community" domain, participants will be asked to assess whether everyone is satisfied rather than simply whether the person responding is satisfied. These more general assessments pertaining to the entire community, Lee and Kim (2016) refer to as "intersubjective community well-being", a point to which we will return in the discussion.

In the next section we will use these characteristics of a well-functioning or thriving community described above to propose a series of items to capture community subjective well-being.

\section{A Template for Community Well-Being}

In this section we present a template for community well-being. As noted above, the conceptualization of community well-being here is intended to be sufficiently abstract and broad that the items could be used in a variety of different community settings e.g. nations, cities, neighborhoods, families, workplaces, schools, religious communities, etc. The items below make reference to "the community." When used in practice with a specific community, e.g. workplace or family, the generic reference to "the community" could be replaced with "the workplace" or "the family" and other appropriate modifications could also be made (e.g. replacing "those in authority" with "parents"). In the generic items given in this section, the expression "the community", that would be replaced in more specific settings, is underlined. In Appendix 1, the various adaptions of the general template for community well-being to specific contexts (city, family, school, etc.) are provided and the changes that were made to the general community subjective well-being template are likewise underlined. Further modification could also be made to the specific versions in the Appendix such as specifying the name of the city (for the city community well-being measure), or simplifying language of the school community well-being measure if it is to be used for middle-school students.

As noted above, the proposed measure is structured around six domains: flourishing individuals, good relationships, proficient leadership, healthy practices, satisfying community, and strong mission. In each of these domains, except the first (the "flourishing individuals" domain), four items, based on the conceptual considerations above, are proposed to assess the domain. This results in 20 items across the final five domains. For the "flourishing individuals" category, various existing individual-level measures of subjective well-being could be used since the literature on individual

\footnotetext{
${ }^{2}$ This sixth domain of a community having a strong mission may be more controversial than the others. However, it is arguably the case that any partnership or community is established for some purpose, or aims at some good or end (Aristotle, fourth C. BCE/1995, I.1.1252a1-7). This in essence is its mission, implicit or explicit. It may be difficult to precisely articulate what the relevant end is across different community contexts. In the case of a city-state, Aristotle took that end to be the making of its citizens good, the promotion of their flourishing (Aristotle, fourth C. BCE/1995).
} 
subjective well-being measures is well-developed (National Research Council 2013; OECD 2013; Allin and Hand 2017; VanderWeele 2017). An example of an individual subjective well-being measure, capturing flourishing individuals using 12 self-report items, that could be used at the individual level is given in Appendix 2 and described in greater detail in VanderWeele (2017). Psychometric properties for the measure (alpha = 0.86) are available elsewhere (Węziak-Białowolska et al. 2019a, 2019b). However, other individual-level well-being measures could also be used instead.

Each of the items below is given a brief descriptive title but these could of course be omitted in the actual administration of the items. The items could be scored $0-10$ and anchored only at the end-points e.g. $0=$ Strongly Disagree, $10=$ Strongly Agree. Alternatively, a smaller number of response options could be used (e.g. 0-6) with each of the responses anchored so that: $0=$ Strongly Disagree, $1=$ Disagree, $2=$ Slightly Disagree, $3=$ Neither Agree or Disagree, $4=$ Slightly Agree, $5=$ Agree, $6=$ Strongly Agree.

\section{The proposed items are as follows:}

Flourishing Individuals:

Average of individual flourishing measures (see individual flourishing measures in Appendix 2).

Good Relationships:

Close Relationships: Everyone has close relationships within the community Respect: Everyone is respected within the community

Trust: Everyone in the community trusts one another

Mutuality: Everyone contributes to the well-being of others in the community

Proficient Leadership:

Beneficence: Those in authority truly care about the well-being of everyone in the community

Integrity: Those in authority in the community can be relied on to do what is right Competence: Those in authority have the skills and understanding they need to lead the community well

Vision: Those in authority are able to inspire the community with their vision

Healthy Practices:

Relational Growth: There are structures and practices in the community that allow relationships to become closer

Fairness: There are structures and practices in place that allow the community to deal with conflicts so that everyone is treated fairly

Sustenance: The community has structures and practices so as to be able to sustain itself 
Achievement: The community has structures and practices that allow it to accomplish its goals

Satisfying Community:

Satisfaction: Everyone is satisfied with the way things are in our community Value: Everyone thinks that this community is a good community to be a part of Belonging: Each person has a sense of belonging in the community

Welcome: There is a sense of welcome in the community so that it is possible for each person to become more integrated over time

Strong Mission:

Purpose: Our community's shared purpose or mission is clear to everyone Contribution: Our community contributes to the world to make it a better place Interconnectedness: Everyone is needed for the community to fulfil its goals and purposes

Synergy: Our community is able to do more with everyone together than we could individually

\section{Discussion: Open Questions and Future Directions}

The proposal above provides a broad conceptualization of community subjective wellbeing that is applicable across different contexts and assesses six domains of community well-being: flourishing individuals, good relationships, proficient leadership, healthy practices, satisfying community, and strong mission. For reasons given above, this conceptualization is arguably more adequate than simply relying on measures of satisfaction with the community alone. We noted above that, in each of these community well-being domains, participants are asked to evaluate the community itself, not simply their satisfaction with it. Even in the "satisfying community" domain, participants are asked to assess whether everyone is satisfied rather than simply whether the person responding is satisfied. These more general assessments pertaining to the entire community, Lee and Kim (2016) refer to as "intersubjective community well-being" and distinguish this from what they refer to, in their work, as "community subjective wellbeing" which are the particular respondent's individual level of satisfaction with e.g. air quality, infrastructure, etc. In the conceptualization given in this paper, these individual assessments of individual satisfaction would fall under, and could be assessed within, the "flourishing individuals" domain. These are, however, simply different ways of categorizing the various relevant constructs. Certainly both are worth examining.

In some settings, one might in principle expect close numeric relations between aggregates of individual level measures as compared with aggregates of "intersubjective" measures. For example, one might hope for rough equality between means of individuals' self-report of their own belonging when averaged over the community with means of individuals' self-report about everyone in the community having a sense of belonging. However, such approximate equality need not always be the case. It may be that the vast majority of a community (perhaps over $80 \%$ ) does feel a sense of 
belonging, but that everyone is likewise aware that a minority do not have this experience, so that the mean of the intersubjective assessments is comparatively low. A simple average of individual perceptions of one's own life or satisfaction may disguise an underlying communal problem; the intersubjective assessment may help uncover this. For example, the vast majority may be dissatisfied with Congress, but happy with their own representative (Mendes 2013). The vast majority may be satisfied with their own healthcare, while acknowledging major problems in the healthcare system itself. For these reasons, the communal or intersubjective measures are thus also worth assessing. They are not necessarily more important than the aggregate of individual perceptions concerning one's own life, but they do convey additional information. Once again, both individual assessment and community or intersubjective assessments are worth examining.

As noted above, for a community to be flourishing - for all aspects of the community's life to be good - both the subjective and the objective indicators of high well-being, at both the communal and individual levels, should be present (see Fig. 1). The proposal here is not to neglect the objective aspects such as literary, or crime, or pollution, but rather to supplement them with both individual- and community- level measures of subjective well-being. Because measures of community subjective wellbeing, beyond community satisfaction, seemed under-developed, the contribution of this paper was to propose a new template to assess such community subjective well-being.

The template proposed was intended to be sufficiently broad and abstract so as to be potentially applicable to different types of communities including nations, cities, neighborhoods, workplaces, families, schools, and religious communities. Its adequacy in each of these settings and the psychometric properties of the measure in these different settings remains to be assessed. It may turn out to be the case that the measure performs more adequately in certain of these community settings than in others.

One might also reasonably wonder whether a measure intended to assess community well-being in these various diverse settings (including nations, cities, neighborhoods, workplaces, families, schools and religious communities) will be adequate. Might different items be required to assess community subjective well-being in these very different settings? Certainly, the concerns of a family are very different from those of a city. While this is indeed so, it may be that those aspects of well-being that are most disparate across settings are, in fact, the objective measures. The relevant objective measures will likely differ; but, arguably, all communities, to be truly flourishing, need flourishing individuals, good relationships, proficient leadership, healthy practices, satisfying community, and strong mission. Again, it is arguably the relevant objective measures that will be more variable. Political participation, cultural offerings, and roadway infrastructure, may be appropriate to nations, cities, and neighborhoods but perhaps less relevant to schools, or to children in families. Other objective indicators such as student-teacher ratios or family dinners, will be applicable to schools or families, but not to workplaces etc. Certain objective aspects of well-being such as health, crime and safety, environment, literacy and education, and economic indicators may be applicable across the different community settings, though the appropriate measures used to operationalize these objective constructs will likely vary across contexts. In any case, a different collection of objective indicators to assess objective well-being will certainly be desirable in different settings, and ideally objective and subjective aspects of well-being should both be assessed. 
An interesting open question for further research and consideration is whether it is indeed the case that the more general abstract domains of community subjective wellbeing described above, in conjunction with an appropriate set of objective measures, are adequate to get a reasonable assessment of communal flourishing, or whether more specific aspects of subjective well-being, tailored and unique to each of the contexts described above (city, family, workplace, etc.) is needed. An advantage of using a common set of items for these six domains of community subjective well-being across contexts is the possibility of establishing in which contexts each domain of subjective well-being is potentially particularly difficult, or easy, to establish.

Considerable work remains of course in establishing the psychometric properties of the proposed measure in different contexts and on assessing the conceptual adequacy, and item consistency, of the six domains above. Establishing psychometric properties with a community construct may also present challenges since the construct, community subjective well-being, although assessed through individual responses, is meant to pertain to the entire community and so the score for a community would in principle be obtained only through an average of a random sample of the relevant community. It may be considerably easier to collect data on numerous distinct communities in certain settings (e.g. families) than in others (e.g. cities or nations).

The use of the measure may be helpful for tracking and assessment purposes and for identifying aspects of a community life that may be most in need of improvement. The use of the measure may also be helpful in assessing whether a community seems, to its members, to be improving or declining over time. The measures are of course of interest in aggregate, but it might also be of interest to examine how assessments of a community vary by age, or gender, or race/ethnicity. It might also be of interest to examine how and whether assessments differ by the total length of time someone has spent in the community. In communities with high turn-over, particular attention may be needed with regard to how to handle newcomers to a community. They may be particularly able to assess whether there is a sense of welcome, but may find it more difficult to assess the general levels of satisfaction of the other members of the community. In principle, the community subjective well-being of a particular community could also be assessed by those who are not in fact members of a community, though in most cases, their knowledge of the community is likely to be more limited. It may also be of interest, and important, to evaluate how assessments of community well-being may differ by whether respondents are, or are not, leaders within the community.

Another interesting and important direction for future research would be the study of the determinants of these various aspects of community well-being in different contexts. With data collected over time, it might be possible to examine which objective indicators seem to contribute most to subjective community well-being, and whether this varies across the domains of community subjective well-being proposed above, and across different contexts such as nations, cities, neighborhoods, workplaces, families, schools and religious communities. Such studies will be important in focusing policy efforts to bring about a greater sense of community well-being. However, to draw reliable causal conclusions, data on community subjective well-being collected repeatedly over time would be needed (VanderWeele 2008; VanderWeele et al. 2016) and in many contexts this could be difficult to obtain.

Another important direction of future research and consideration is the relation between individual well-being and community well-being. As noted above, there are difficult conceptual questions concerning these relations. The two are certainly interrelated, both 
conceptually and causally. A community is arguably not flourishing if its constituent members are not flourishing. The relation is conceptual. Likewise, for at least certain persons, they may not say that "all aspects of my life are good" if their community is not thriving. Here too the relation is conceptual: the community's well-being is a constituent component of the individual's subjective well-being. However, there are also causal relations governing the dynamics between individual and community subjective well-being. A wellfunctioning community will often be causally relevant to (e.g. causally improve) an individual's subjective well-being, in the form of pleasant interactions, or cleanliness of spaces, or availability of jobs, or opportunities to advance. Likewise individual well-being will often have a causal impact on communal well-being. An individual's sense of purpose, or pursuit of the good, for example, may alter the extent to which she or he contributes to the community, tries to make it a better place, or helps others.

Similar issues concerning causal relationships likewise pertain also to objective measures of community well-being. An individual's subjective well-being may lead to greater contributions to a country's educational system or economic progress or the prevention of air pollution. However, likewise a community's educational or economic opportunities will in turn enhance an individual's subjective well-being as well as objective individual measures such as their actual educational attainment, income, or longevity. In much of the research on social capital (Portes 1998; Berkman et al. 2014; Kawachi et al. 2008; Gilbert et al. 2013), the communal or social relations are viewed principally as a means to economic, health, or other individual goods or ends. Indeed the very term "social capital" suggests that it is conceived of as a means. However, community well-being is arguably not simply a means but also an end in and of itself. While it certainly can be a means to other ends, it is also something that is to be sought for its own sake. The notion, and language, of "social cohesion" (Friedkin 2004; Berkman et al. 2014) perhaps comes closer to the broader concept of community subjective well-being. An extensive literature has likewise examined its effects on individual health and well-being outcomes (Meijer et al. 2012; Berkman et al. 2014). However social cohesion is arguably more narrowly focused on certain aspects of community well-being pertaining to relationships, similarity, and belonging, with perhaps often less focus on authority and leadership, structures and practices, and a sense of mission. The notion of "collective efficacy" (Sampson et al. 1997; Bandura 2000; Goddard et al. 2004) perhaps better captures some of these latter aspects. In any case, it would be of interest also in future research to examine how the various aspects of community well-being relate to different individual-level outcomes, and vice versa.

The extent of these causal and conceptual relations may vary across individuals and across communities. The conceptual relations concerning the extent to which communal well-being is a constitutive component of individual well-being might well be stronger in collectivist societies than in individualist societies (Suh et al. 1998). The ways in which a community's well-being causally affects an individual's well-being may be stronger for someone who is disadvantaged or needy than for someone who is relatively wealthy and seemingly less dependent on the community. Likewise the extent to which an individual's subjective well-being causally alters the community's thriving may vary across settings. Someone with a strong sense of purpose may be more likely to substantially causally alter a community's well-being in a democracy than in a dictatorship. The relations between communal well-being and individual well-being are both causal and conceptual, and the extent of these relations will vary across settings and individuals. 
However, when community well-being is treated as an outcome for a community, it is important, conceptually, to include within this as well measures of individual wellbeing. A community is not fully thriving if its members are not. The measure proposed above thus includes, as one of several domains, "flourishing individuals" with the understanding that previously developed individual level measures of subjective wellbeing could be used for these. It would of course be possible to make use of the measures above while excluding the aggregate of these individual level measures of subjective well-being. In assessing causal relations and effects of community versus individual well-being on other (perhaps objective) outcomes, it may be of interest to treat these individual and community subjective well-being separately. However again, when the goal is an aggregate measure of community well-being, as an outcome, it is arguably reasonable to treat aggregate summaries of individual well-being as one of the categories of community well-being.

The hope for the proposed community subjective well-being measure is that it would be useful in tracking community well-being over time, in assessment and reflection, and ultimately in identifying determinants of community well-being and appropriately intervening to improve it. The success of this approach will depend in part on measure validation for these various uses, and in different community contexts, on obtaining appropriate data over time, and on appropriately relating objective and subjective measures and meeting challenges present in subjective well-being research more generally. White (2010) has argued that although subjective well-being approaches have tremendous potential to transform policy considerations, there are potential dangers inherent in the approach that must be navigated as well. These include blaming individuals for their condition or the way they feel, or ignoring the concept of wellbeing until basic needs are met, or conversely dismissing it because subjective wellbeing can sometimes be high even if material conditions are poor, or dismissing it on the grounds of its being too broad to be relevant for policy. Progress on better measures of, and a better understanding of, subjective well-being, both at the individual and at the community level, will be useful in helping to meet and navigate these challenges. With time, data collection on appropriate measures, and research, we will hopefully come to a better understanding of the determinants of community well-being itself, what might be most lacking in different contexts, and how to improve it.

Acknowledgements The author thanks the participants of the workshop on "Health and Happiness in Policy and Practice Across the Globe: The Role of Science and Evidence" hosted by the Lee Kum Sheung Center for Health and Happiness at Harvard University, April 12, 2019, for helpful feedback on the proposed measure; Matthew Lee, Eileen McNeely, Michael Balboni, and members of the Human Flourishing Program at Harvard University for helpful discussions on the conceptualization of community well-being; and members of the Columbus Foundation for further feedback on the specific items employed in the measure.

Funding The present research was funded by John Templeton Foundation grant 61075.

\section{Compliance with Ethical Standards}

Conflict of Interest The author declares no conflicts of interest.

Ethics Approval and Consent to Participate The research in this paper has not involved human subjects and there is thus no informed consent. 


\section{Appendix 1: Communal Well-Being Measures Adapted for National, City, Neighborhood, Workplace, Family, School, and Religious Community Contexts}

\section{National Community Well-Being}

Flourishing Individuals:

Average of individual flourishing measures (see individual flourishing measures)

Good Relationships:

Close Relationships: Everyone in the nation has close relationships

Respect: Everyone in the nation is respected

Trust: Everyone in the nation trusts one another

Mutuality: Everyone in the nation contributes to the well-being of others

Proficient Leadership:

Beneficence: Those in authority truly care about the well-being of everyone in the nation Integrity: Those in authority in the nation can be relied on to do what is right

Competence: Those in authority have the skills and understanding they need to lead the nation well

Vision: Those in authority are able to inspire the nation with their vision

Healthy Practices:

Relational Growth: There are national structures and practices that allow relationships to become closer

Fairness: There are structures and practices in place that allow the nation to deal with conflicts so that everyone is treated fairly

Sustenance: The nation has structures and practices so as to be able to sustain itself Achievement: The nation has structures and practices that allow it to accomplish its goals

Satisfying Community:

Satisfaction: Everyone is satisfied with the way things are in our nation

Value: Everyone thinks that this nation is a good community to be a part of

Belonging: Each person in the nation has a sense of belonging

Welcome: There is a sense of welcome in the nation so that it is possible for each person to become more integrated over time

Strong Mission:

Purpose: Our nation's shared purpose to enhance the well-being of all and of our country is clear to everyone 
Contribution: Our nation contributes to the world to make it a better place Interconnectedness: Everyone is needed for the nation to fulfil its goals and purposes Synergy: Our nation is able to do more with everyone together than we could individually

\section{City Community Well-Being}

Flourishing Individuals:

Average of individual flourishing measures (see individual flourishing measures)

Good Relationships:

Close Relationships: Everyone has close relationships within the city

Respect: Everyone is respected within the city

Trust: Everyone in the city trusts one another

Mutuality: Everyone contributes to the well-being of others in the city

Proficient Leadership:

Beneficence: Those in authority truly care about the well-being of everyone in the city Integrity: Those in authority in the city can be relied on to do what is right

Competence: Those in authority have the skills and understanding they need to lead the city well

Vision: Those in authority are able to inspire the city with their vision

Healthy Practices:

Relational Growth: There are structures and practices in the city that allow relationships to become closer

Fairness: There are structures and practices in place that allow the city to deal with conflicts so that everyone is treated fairly

Sustenance: The city has structures and practices so as to be able to sustain itself

Achievement: The city has structures and practices that allow it to accomplish its goals

Satisfying Community:

Satisfaction: Everyone is satisfied with the way things are in our city

Value: Everyone thinks that this city is a good community to be a part of

Belonging: Each person has a sense of belonging in the city

Welcome: There is a sense of welcome in the city so that it is possible for each person to become more integrated over time

Strong Mission:

Purpose: Our city's shared purpose to be a good place to live is clear to everyone Contribution: Our city contributes to the world to make it a better place 
Interconnectedness: Everyone is needed for the city to fulfil its goals and purposes Synergy: Our city is able to do more with everyone together than we could individually

\section{Neighborhood Community Well-Being}

Flourishing Individuals:

Average of individual flourishing measures (see individual flourishing measures)

Good Relationships:

Close Relationships: Everyone has close relationships within the neighborhood Respect: Everyone is respected within the neighborhood

Trust: Everyone in the neighborhood trusts one another

Mutuality: Everyone contributes to the well-being of others in the neighborhood

Proficient Leadership:

Beneficence: Those in authority truly care about the well-being of everyone in the neighborhood

Integrity: Those in authority in the neighborhood can be relied on to do what is right Competence: Those in authority have the skills and understanding they need to lead the neighborhood well

Vision: Those in authority are able to inspire the neighborhood with their vision

Healthy Practices:

Relational Growth: There are structures and practices in the neighborhood that allow relationships to become closer

Fairness: There are structures and practices in place that allow the neighborhood to deal with conflicts so that everyone is treated fairly

Sustenance: The neighborhood has structures and practices so as to be able to sustain itself Achievement: The neighborhood has structures and practices that allow it to accomplish its goals

Satisfying Community:

Satisfaction: Everyone is satisfied with the way things are in our neighborhood Value: Everyone thinks that this neighborhood is a good community to be a part of Belonging: Each person has a sense of belonging in the neighborhood

Welcome: There is a sense of welcome in the neighborhood so that it is possible for each person to become more integrated over time

Strong Mission:

Purpose: Our neighborhood's shared purpose to be a good place to live is clear to everyone 
Contribution: Our neighborhood contributes to the world to make it a better place Interconnectedness: Everyone is needed for the neighborhood to fulfil its goals and purposes

Synergy: Our neighborhood is able to do more with everyone together than we could individually

\section{Workplace Community Well-Being}

Flourishing Individuals:

Average of individual flourishing measures (see individual flourishing measures)

Good Relationships:

Close Relationships: Everyone has close relationships within the workplace

Respect: Everyone is respected at work

Trust: Everyone at work trusts one another

Mutuality: Everyone contributes to the well-being of others at work

Proficient Leadership:

Beneficence: Management truly cares about the well-being of everyone at work Integrity: Management can be relied on to do what is right

Competence: Those in management have the skills and understanding they need to lead well

Vision: Those in management are able to inspire employees with their vision

Healthy Practices:

Relational Growth: There are structures and practices in the workplace that allow relationships to become closer

Fairness: There are structures and practices in place that allow employees to deal with conflicts so that everyone is treated fairly

Sustenance: The workplace has structures and practices so that it is not in danger of closure

Achievement: The workplace has structures and practices that allow employees to achieve their goals

Satisfying Community:

Satisfaction: Everyone is satisfied with the way things are in our workplace Value: Everyone thinks that this workplace is a good community to be a part of Belonging: Each person has a sense of belonging in the workplace Welcome: There is a sense of welcome in the workplace so that it is possible for each person to become more integrated over time 
Mission:

Purpose: The mission of our company is clear to everyone Contribution: Our company contributes to the world to make it a better place Interconnectedness: Everyone is needed for the company to fulfil its goals and purposes Synergy: Our company is able to do more with everyone together than we could individually

\section{Family Community Well-Being}

Flourishing Individuals:

Average of individual flourishing measures (see individual flourishing measures)

Good Relationships:

Close Relationships: Everyone has close relationships within the family Respect: Everyone is respected within the family

Trust: Everyone in the family trusts one another

Mutuality: Everyone contributes to the well-being of others in the family

Proficient Leadership:

Beneficence: The parents truly care about the well-being of everyone in the family Integrity: The parents can be relied on to do what is right

Competence: The parents have the skills and understanding they need to lead the family well

Vision: The parents are able to inspire the members of the family

Healthy Practices:

Relational Growth: There are family practices that allow relationships to become closer Fairness: There are family practices in place that allow the community to deal with conflicts so that everyone is treated fairly

Sustenance: The family has structures and practices so as to be able to sustain itself Achievement: The family has structures and practices that allow each person to accomplish their goals

Satisfying Community:

Satisfaction: Everyone is satisfied with the way things are in our family Value: Everyone thinks that this family is a good community to be a part of Belonging: Each person has a sense of belonging in the family Welcome: There is a sense of welcome in the family so that it is possible for each person to become more integrated over time 
Strong Mission:

Purpose: The family's shared purpose of nurturing relationships and each person is clear to everyone

Contribution: Our family contributes to the world to make it a better place

Interconnectedness: Everyone is needed for the family to fulfil its goals and purposes

Synergy: Our family is able to do more with everyone together than we could individually

\section{School Community Well-Being}

Flourishing Individuals:

Average of individual flourishing measures (see individual flourishing measures)

Good Relationships:

Close Relationships: Everyone has close relationships within the school

Respect: Everyone is respected within the school

Trust: Everyone in the school trusts one another

Mutuality: Everyone contributes to the well-being of others in the school

Proficient Leadership:

Beneficence: Those in leadership truly care about the well-being of everyone in the $\underline{\text { school }}$

Integrity: Those in leadership can be relied on to do what is right

Competence: Those in leadership have the skills and understanding they need to lead the school well

Vision: Those in leadership are able to inspire the school with their vision

Healthy Practices:

Relational Growth: There are structures and practices in the school that allow relationships to become closer

Fairness: There are structures and practices in place that allow the school to deal with conflicts so that everyone is treated fairly

Sustenance: The school has structures and practices so as to be able to sustain itself Achievement: The school has structures and practices that allow it to accomplish its goals

Satisfying Community:

Satisfaction: Everyone is satisfied with the way things are in our school Value: Everyone thinks that this school is a good community to be a part of Belonging: Each person has a sense of belonging in the school 
Welcome: There is a sense of welcome in the school so that it is possible for each person to become more integrated over time

Strong Mission:

Purpose: Our school's shared purpose or mission is clear to everyone Contribution: Our school contributes to the world to make it a better place Interconnectedness: Everyone is needed for the school to fulfil its goals and purposes Synergy: Our school is able to do more with everyone together than we could individually

\section{Religious Community Well-Being}

Note: The items below are phrased specifically with regard to a "church," but when used in other settings, "church" could be replaced by e.g. "synagogue", "mosque", etc.

Flourishing Individuals:

Average of individual flourishing measures (see individual flourishing measures)

Good Relationships:

Close Relationships: Everyone has close relationships within the church

Respect: Everyone is respected within the church

Trust: Everyone in the church trusts one another

Mutuality: Everyone contributes to the well-being of others in the church

Proficient Leadership:

Beneficence: Those in authority truly care about the well-being of everyone in the church

Integrity: Those in authority in the church can be relied on to do what is right

Competence: Those in authority have the skills and understanding they need to lead the church well

Vision: Those in authority are able to inspire the church with their vision

Healthy Practices:

Relational Growth: There are structures and practices in the church that allow relationships to become closer

Fairness: There are structures and practices in place that allow the church to deal with conflicts so that everyone is treated fairly

Sustenance: The church has structures and practices so as to be able to sustain itself Achievement: The church has structures and practices that allow it to accomplish its goals 
Satisfying Community:

Satisfaction: Everyone is satisfied with the way things are in our church community Value: Everyone thinks that this church is a good community to be a part of Belonging: Each person has a sense of belonging in the community Welcome: There is a sense of welcome in the community so that it is possible for each person to become more integrated over time

Strong Mission:

Purpose: Our church's shared mission is clear to everyone Contribution: Our church contributes to the world to make it a better place Interconnectedness: Everyone is needed for the church to fulfil its goals and purposes Synergy: Our church is able to do more with everyone together than we could individually

\section{Appendix 2: An Individual-Level Subjective Measure of Flourishing that Can be Included in Assessing Communal Well-Being}

The following twelve items (VanderWeele 2017; VanderWeele et al. 2019) could be used as an assessment for individual level flourishing, for the "flourishing individuals" domain of the community well-being assessment. The 12 items assess several important domains of individual flourishing including: Happiness and Life Satisfaction (Items 1-2), Mental and Physical Health (3-4), Meaning and Purpose (5-6), Character and Virtue (7-8), and Close Social Relationships (9-10). A sixth domain, Financial and Material Stability (11-12) is an important means in sustaining the other domains over time. The background and motivation for these items and the flourishing domains can be found in VanderWeele (2017) and VanderWeele et al. (2019). ${ }^{3}$

Please respond to the following questions on a scale from 0 to 10 :

1. Overall, how satisfied are you with life as a whole these days?

$0=$ Not Satisfied at All, $10=$ Completely Satisfied

2. In general, how happy or unhappy do you usually feel?

$0=$ Extremely Unhappy, $10=$ Extremely Happy

\footnotetext{
${ }^{3}$ In school or family settings, in which individual flourishing is being assessed for adolescents (age 12-18), rather than adults, it will be desirable to modify some of these items due to developmental stage. It is proposed that item 2 be replaced with "In general I consider myself a happy person." $(0=$ Strongly Disagree, $10=$ Strongly Agree); item 6 be replaced with "I am doing things now that will help me achieve my goals in life." $(0=$ Strongly Disagree, $10=$ Strongly Agree); item 10 be replaced with "I have people in my life I can talk to about things that really matter." $(0=$ Strongly Disagree, $10=$ Strongly Agree); and item 11 be replaced with "My family has enough money to live a truly decent life." ( $0=$ Strongly Disagree, $10=$ Strongly Agree $)$. These new items were adapted from other measures (Item 2: Lyubomirsky and Lepper (1999); Items 6 and 10: Carle et al. (2014); Item 11: Patrick et al. (2002)).
} 
3. In general, how would you rate your physical health?

$0=$ Poor, $10=$ Excellent

4. How would you rate your overall mental health?

$0=$ Poor, $10=$ Excellent

5. Overall, to what extent do you feel the things you do in your life are worthwhile?

$0=$ Not at All Worthwhile, $10=$ Completely Worthwhile

6. I understand my purpose in life.

$0=$ Strongly Disagree, $10=$ Strongly Agree

7. I always act to promote good in all circumstances, even in difficult and challenging situations.

$0=$ Not True of Me, $10=$ Completely True of Me

8. I am always able to give up some happiness now for greater happiness later.

$0=$ Not True of Me, $10=$ Completely True of Me

9. I am content with my friendships and relationships.

$0=$ Strongly Disagree, $10=$ Strongly Agree

10. My relationships are as satisfying as I would want them to be.

$0=$ Strongly Disagree, $10=$ Strongly Agree

11. How often do you worry about being able to meet normal monthly living expenses?

$0=$ Worry All of the Time, $10=$ Do Not Ever Worry

12. How often do you worry about safety, food, or housing?

$0=$ Worry All of the Time, $10=$ Do Not Ever Worry

Open Access This article is distributed under the terms of the Creative Commons Attribution 4.0 International License (http://creativecommons.org/licenses/by/4.0/), which permits unrestricted use, distribution, and reproduction in any medium, provided you give appropriate credit to the original author(s) and the source, provide a link to the Creative Commons license, and indicate if changes were made. 


\section{References}

Allin, P., \& Hand, D. J. (2017). New statistics for old? - measuring the wellbeing of the UK. Journal of the Royal Statistical Society, Series A, 180, 1-22.

Aristotle (4th C. BCE/1995). The politics of Aristotle. Barker, E. (trans.). Oxford: Oxford University Press.

Bandura, A. (2000). Exercise of human agency through collective efficacy. Current Directions in Psychological Science, 9(3), 75-78.

Berkman, L. F., Kawachi, I., \& Glymour, M. M. (2014). Social Epidemiology. New York: Oxford University Press.

Carle, A., McIntosh, H., Moore, K. A., Lippman, L., Guzman, L., Ramos, M. F., Kuhfeld, M., Ryberg, R., \& Caal, S. (2014). Flourishing children: Defining and testing indicators of positive development. New York: Springer.

Chanan, G. (2002). Community development foundation measure of community: A study for the active community unit and research. London: Development and Statistics Unit of the Home Office.

Cox, D., Frere, M., West, S., \& Wiseman, J. (2010). Developing and using local community wellbeing indicators: Learning from the experiences of community indicators Victoria. Australian Journal of Social Issues, 45, 71-89.

Friedkin, N. E. (2004). Social cohesion. Annual Review of Sociology, 30, 409-425.

Gilbert, K. L., Quinn, S. C., Goodman, R. M., Butler, J., \& Wallace, J. (2013). A meta-analysis of social capital and health: A case for needed research. Journal of Health Psychology, 18(11), 1385-1399.

Goddard, R. D., Hoy, W. K., \& Hoy, A. W. (2004). Collective efficacy beliefs: Theoretical developments, empirical evidence, and future directions. Educational Researcher, 33(3):3-13, 3.

Hay, D. I. (1996). Keep it grounded and keep it simple: Measuring community well-being. Vancouver: Social Planning and Research Council of British Columbia.

Kawachi, I., Subramanian, S. V., \& Kim, D. (2008). Social capital and health (1st ed.). New York: Springer.

Kim, Y., \& Lee, S. J. (2014). The development and application of a community wellbeing index in Korean metropolitan cities. Social Indicators Research, 119, 533-558.

Lee, S.J. and Kim, Y. (2016). Structure of well-being: An exploratory study of the distinction between individual well-being and community well-being and the importance of intersubjective community well-being. In: Y. Kee, S.J. Lee, and R. Phillips (Eds.): Social factors and community well-being. Springer: Switzerland. Chapter 2, p. 13-37.

Lyubomirsky, S., \& Lepper, H. (1999). A measure of subjective happiness: Preliminary reliability and construct validation. Social Indicators Research, 46, 137-155.

McHardy, M., \& O’Sullivan, E. (2004). Five Nations community well-being in Canada: The community wellbeing index (CWB), 2001. Indian and northern affairs Canada: Strategic research and analysis directorate. Ottawa: Published under the authority of the Minister of Indian Affairs and Northern Development. Available at: http://citeseerx.ist.psu.edu/viewdoc/download?doi=10.1.1.528.9225\&rep=rep1\&type=pdf. Accessed 16 Aug 2019.

Meijer, M., Röhl, J., Bloomfield, K., \& Grittner, U. (2012). Do neighborhoods affect individual mortality? A systematic review and meta-analysis of multilevel studies. Social Science and Medical, 74(8), 1204-1212.

Mendes, E. (2013). Americans down on congress, OK with own representative. Gallup poll report, 2013: Last accessed July 26, 2019: https:/news.gallup.com/poll/162362/americans-down-congress-ownrepresentative.aspx.

National Research Council. (2013). Subjective well-being. Washington, DC: National Academies Press.

OECD Guidelines on Measuring Subjective Well-Being (OECD Publishing, Paris), 2013.

Patrick, D. L., Edwards, T. C., \& Topolski, T. D. (2002). Adolescent quality of life, part II: Initial validation of a new instrument. Journal of Adolescence, 25, 287-300.

Phillips, R., \& Wong, C. (2017). Handbook of community well-being research. Dordrecht: Springer.

Portes, A. (1998). Social capital: Its origins and applications in modern sociology. Annual Review of Sociology, 24(1), 1-24.

Prilleltensky, I., \& Prilleltensky, O. (2006). Promoting well-being: Linking personal, organizational, and community change. Hoboken: Wiley.

Sampson, R. J., Raudenbush, S. W., \& Earls, F. (1997). Neighborhoods and violent crime: A multilevel study of collective efficacy. Science, 277(5328), 918-924.

Sirgy MJ, Widgery RN, Lee D-J, Yu GB. (2010). Developing a Measure of Community Well-Being Based on Perceptions of Impact in Various Life Domains. Soc Indic Res 96:295-311.

Suh, E., Diener, E., Oishi, S., \& Triandis, H. C. (1998). The shifting basis of life satisfaction judgments across cultures: Emotions versus norms. Journal of Personality and Social Psychology, 74(2), 482-493.

VanderWeele, T. J. (2008). Ignorability and stability assumptions in neighborhood effects research. Statistics in Medicine, 27, 1934-1943. 
VanderWeele, T. J. (2017). On the promotion of human flourishing. PNAS, 114(31), 8148-8156.

VanderWeele, T. J., Jackson, J. W., \& Li, S. (2016). Causal inference and longitudinal data: A case study of religion and mental health. Social Psychiatry and Psychiatric Epidemiology, 51, 1457-1466.

VanderWeele, T. J., McNeely, E., \& Koh, H. K. (2019). Reimagining health - Flourishing. JAMA, 321(17), $1667-1668$.

Węziak-Białowolska, D., McNeely, E., \& VanderWeele, T. J. (2019a). Flourish index and secure flourish index - Validation in workplace settings. Cogent Psychology, 6, 1598926.

Węziak-Białowolska, D., McNeely, E., and VanderWeele, T.J. (2019). Human flourishing in cross cultural settings: evidence from the US, China, Sri Lanka, Cambodia and Mexico. Frontiers in Psychology, 10 (Article 1269): 1-13.

White, S. C. (2010). Analysing wellbeing: A framework for development practice. Development in Practice, $20,158-172$.

Publisher's Note Springer Nature remains neutral with regard to jurisdictional claims in published maps and institutional affiliations. 